\title{
Establishing a Supply of Plutonium-238 and Associated Radioisotope Power Systems \\ Capabilities and Policy Improvements- A Multi-part Success Story
}

Thomas J. Sutliff

The Aerospace Corporation

(330) 461-8441

tsutliff@,nasa.gov

Peter W. McCallum

The Aerospace Corporation

Stephen G. Johnson, Ph.D.

Department of Energy/Idaho National Laboratory 


\section{Executive Summary}

Around the time of the last Planetary Science Decadal Survey, NASA and the Department of Energy (DOE) developed a strategy to modernize production of radioisotope power systems (RPS) for planned space science and exploration missions. Over the last 4 years, NASA and DOE successfully implemented this strategy, including reestablishing domestic production of plutonium-238 $\left(\mathrm{Pu}-238\right.$ or $\left.{ }^{238} \mathrm{Pu}\right)$, modernizing production equipment for fueled clad and component manufacturing, expanding plutonium shipment capabilities, and deploying a constantrate production operational model versus a campaign-based production model, all with the effect of reducing mission costs and associated schedule risks.

This white paper describes the investments made and some successes achieved over the last 10 years to enable continued exploration of the solar system using radioisotope power systems.

\section{Background}

The RPS Program was established in 2009 to integrate and manage RPS investments for NASA to ensure RPS availability for the exploration of the solar system in environments where conventional solar or chemical power generation is impractical or impossible, such as where the Sun's intensity is either too dim, obscured, or otherwise inadequate. The RPS Program is a multi-center and multiagency program. NASA partners with DOE's Office of Nuclear Energy to provide technologically robust nuclear power system solutions to robotic spacecraft and exploration missions. The NASADOE partnership is formally established through an interagency Memorandum of Understanding (MOU). MOUs have existed for over 50 years between NASA and DOE. ${ }^{1}$ In 1965 an MOU first set context for "Isotopic SNAP Devices for NASA Space Vehicles". The most recent 2016 MOU reaffirms the roles of NASA and DOE in providing these space nuclear power systems for NASA's missions, provide the basis for working together.

Per U.S. policy, the DOE maintains, on a full cost recovery basis, the capability and infrastructure to develop, furnish, and conduct safety analyses for space nuclear systems for use in U.S. Government space systems. For NASA, DOE has continued to maintain RPS capabilities to make possible its missions. DOE has provided 46 power systems for 27 U.S. space missions (as of August 1, 2020) since the initial use of RPS in 1961, with missions lasting much longer than the original design life due to the robust technology and long-lived $\mathrm{Pu}-238$ radioisotope. These RPS have enabled and will enable scientists to collect data that have rewritten textbooks and revised our collective understanding of our solar system and beyond.

\section{The Problem and Related Concerns (circa 2009)}

Just as the RPS Program was established, and because the Pu-238 domestic production capability was suspended in the late 1980's and foreign purchases became an unreliable option, the National Research Council (NRC) published its 2009 report "Radioisotope Power Systems: An Imperative for Maintaining U.S. Leadership in Space Exploration" "2 wherein a high priority recommendation was:

"HIGH-PRIORITY RECOMMENDATION. Plutonium-238 Production. The fiscal year 2010 federal budget should fund the DOE to reestablish production of ${ }^{238} \mathrm{Pu}$."

Thus, resuming domestic production of Pu-238 became a critical factor in NASA-DOE RPS interactions at the time of the last Planetary Science Decadal Survey. In parallel, there were 
concerns regarding the domestic RPS capabilities as the operating model was based on a campaign-model leveraging equipment that was at the end of its lifetime, resulting in costly startup and shutdown activities to hire and train operators; maintain, requalify and replace equipment; and integrate RPS production operations within established facility plans. These conditions resulted in increased costs and risks to NASA missions that were required to integrated RPS production requirements within their overall cost model.

\section{The Path Forward}

In Fiscal Year 2012, Congress authorized funding to reconstitute the capability to domestically produce $\mathrm{Pu}-238$ and re-establish technical capabilities necessary for RPS production. ${ }^{3}$ These efforts proved successful when in December 2015, 50 grams of new plutonium dioxide $\left(\mathrm{PuO}_{2}\right)$ was produced at Oak Ridge National Laboratory $(\mathrm{ORNL})$. $\left(\mathrm{PuO}_{2}\right.$ represents the chemistry of the $\mathrm{Pu}-238$ in the state required for later processing.) Ensuing successful production campaigns of 50, 100 and 220 g established a repeatable, scalable process. Increasing production rates per year are being pursued, with average annual near-term targets of $400 \mathrm{~g} \mathrm{PuO}_{2}$ growing to an average sustained annual average rate of $1.5 \mathrm{~kg}$ by the end of 2026 to meet need. This rate was sized to meet NASA mission cadence and can be adjusted up or down based on forecasted need. The increase in production rate is enabled by use of two existing irradiation reactors, the High Flux Isotope Reactor (HFIR) at ORNL and the Advanced Test Reactor (ATR) at Idaho National Laboratory (INL). Expansion of target production and chemical separation capabilities at ORNL, through both increases in hardware and in staffing similarly contribute to the production ramp-up efforts. The HFIR target irradiation capacity will also increase after a planned reflector changeout, and ATR is conducting target qualification in multiple reactor positions. Both of these activities provide maximum flexibility to support $\mathrm{Pu}-238$ production.

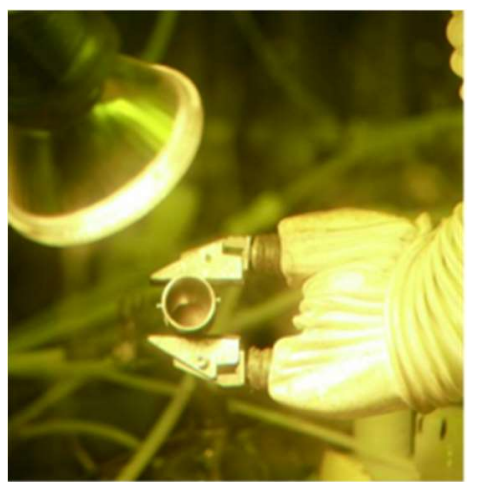

Figure 1: First new $\mathrm{PuO}_{2}$ in hot cell manipulator (ORNL, 2015).

NASA's and DOE's renegotiated agreement to align roles and responsibilities of both agencies via the 2016 MOU update produced an improved business model establishing clear milestones, deliverables and accountability as isotope production ramped up. This resulted in DOE establishing a multi-laboratory integrated plan that highlights production and infrastructure investments, opportunities for shared costs, and modernization of processes and facilities (Los Alamos National Laboratory (LANL) processing facilities, ORNL target fabrication, INL fueling and testing, etc.). This coordinated effort included DOE developing a formal Integrated Program Plan and NASA and DOE identifying and mitigating shared risks associated with Pu-238 and RPS production. This improved roadmap and communication allowed the DOE and NASA to shift to a production model that aimed to reduce mission risks and costs.

\section{$\underline{\text { Status }}$}

\section{DOE Production Operations}

By late 2017, a renewed supply of $\mathrm{PuO}_{2}$ had been established and production was being scaled up. With the operational costs attributed to NASA and its users, DOE and NASA sought out efficiencies and collaboratively defined and established a Constant Rate Production (CRP) operations approach that leveraged the standard DOE business and operational models. ${ }^{4}$ CRP 
integrates all production elements, establishing a balanced fueled clad production rate across the DOE labs, based on an annually updated $10+$ year projection of NASA mission needs for RPS.

The CRP methodology generates $\mathrm{PuO}_{2}$ each year based on irradiation of neptunium-237 targets in the ORNL and INL reactors. ORNL is conducting its fifth campaign of target processing, chemically extracting new $\mathrm{PuO}_{2}$, while recycling neptunium for reirradiation. Ongoing target fabrication. irradiation and chemical separation have yielded $770 \mathrm{~g}$ of $\mathrm{PuO}_{2}$ to date. $\mathrm{The}^{\mathrm{PuO}} \mathrm{O}_{2}$ is then shipped to LANL to be made into heat sources known as fueled clads (FC). Next, these FCs are sent to INL where they are placed into a stable storage state and remain ready to be made into General Purpose Heat Source (GPHS) modules for fueling an identified mission's RPS. Newly made $\mathrm{PuO}_{2}$ at ORNL is produced at a higher heat-inventory per weight and can be blended with lower heat-inventory stock at LANL. Blending enables use of all available $\mathrm{PuO}_{2}$ while maintaining consistency with NASA's heat source criteria for missions. Thus, blending allows more fueled clads to be produced per quantity of newly manufactured $\mathrm{PuO}_{2}$ than possible from new production alone. A nuclear materials management database is used to manage and project heat source needs against potential mission usage, right-sizing the production processes. This CRP approach also maintains a stable, qualified workforce, reducing risk of suffering cyclical staffing issues within the RPS infrastructure and reduces the direct cost of an RPS to an individual NASA mission.

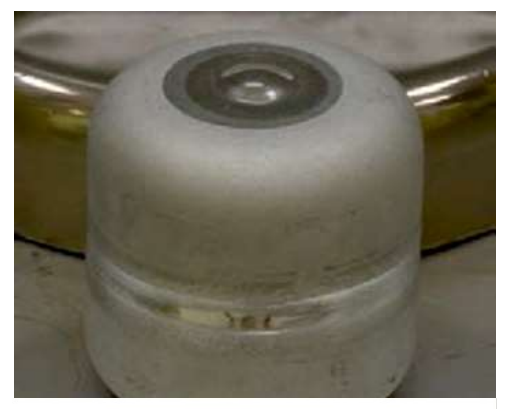

Figure 2: A Flight Fueled Clad destined for Mars (LANL, 2017)

The implementation of the CRP operations model leads to annual shipments of FCs from LANL to INL that precede mission need dates by 2-4 years, reducing mission schedule risk, consequences of supply chain issues, etc. Production of heat sources will be part of an annual campaign that include most of the process to construct GPHS modules stopping just short of final assembly, with placement of the FCs into graphite impact shells. These fueled graphite shells are then placed onto a module reduction manifold where they are subjected to environmental conditions that prepare the $\mathrm{PuO}_{2}$ for use in an RPS. This storage condition is stable and allows use in the future for a new mission.

The annual CRP activities serve both the goal of maintaining qualifications of the workforce and of ensuring that there is "product on the shelf" to reduce the RPS production ramp-up time required for a mission. The costs for these flight FC are borne by the NASA RPS Program, with commensurate savings to missions subsequently using the heat sources already in inventory.

When a mission is confirmed, INL plans for final assembly of the GPHS modules by inventorying the various graphite impact shells at INL and writing of a build plan. The build plan defines specific sequential steps for final assembly and fueling of the generator(s) from the available shells, allowing any mission-specific accommodations to be made at that time.

Of note, after demonstration of the initial $\mathrm{Pu}-238$ production capability, the Government Accountability Office (GAO) reviewed RPS and $\mathrm{Pu}-238$ production plans supporting future NASA missions, issuing a 2017 report. ${ }^{5}$ GAO made three recommendations, including that DOE develop a plan with milestones and interim steps for its $\mathrm{Pu}-238$ and RPS production approach and that DOE 
assess the long-term effects of known production challenges and communicate these effects to NASA. The CRP approach outlined above, along with establishment of a shared (NASA-DOE) continuous risk management approach, addressed the GAO recommendations.

\section{Mission Implementation}

The physical and personnel capabilities of DOE production operations continue to meet NASA requirements. The RPS capabilities shared between DOE and the RPS Program are sustained to support both current and future NASA mission needs.

The Multi-Mission Radioisotope Thermoelectric Generator (MMRTG) is the current RPS

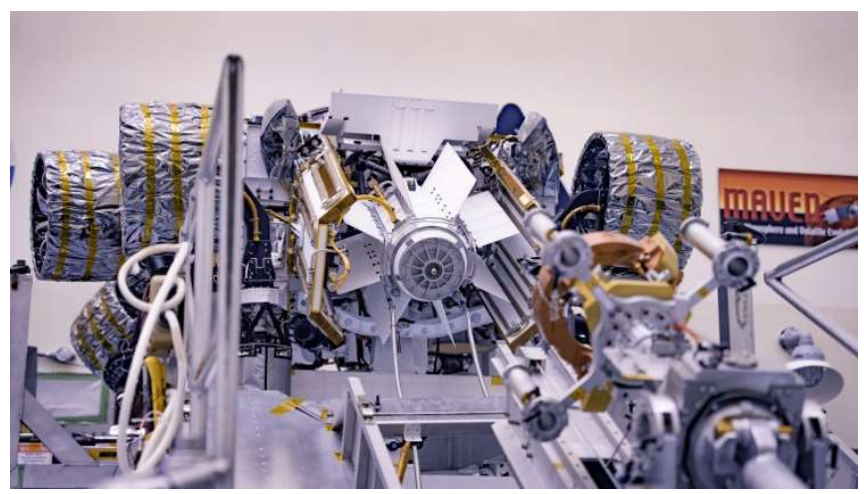

Figure 3: Perseverance rover's MMRTG hot fit check (KSC, 2020) available to missions. The MMRTG utilizes $2000 \mathrm{~W}_{\text {th }}$ of heat from $4.8 \mathrm{~kg}$ of $\mathrm{PuO}_{2}$ to generate a nominal beginning of mission power of $110 \mathrm{~W}_{\mathrm{e}}$. The first MMRTG flown, fueled nearly 12 years ago, has been continuously operating and powering the Curiosity rover since it landed on Mars in 2012. A second MMRTG was fueled, tested, delivered and integrated to the Perseverance rover prior to its launch to Mars on July 30, 2020. A portion of the new ORNLproduced $\mathrm{PuO}_{2}$ was used within the fueled clads for the Perseverance MMRTG.

After the New Frontiers-3 (NF-3) Announcement of Opportunity (AO, 2009) excluded use of an RPS (a mission-limiting decision), the user community welcomed news in the 2016 NF-4 AO that proposing teams could baseline up to three MMRTGs and/or over 40 light weight radioisotope heater units (LWRHUs) for use if such capability was mission enabling. Multiple missions proposed the use of at least one RPS. Ultimately the selected mission, Dragonfly, benefitted from this opportunity and baselined one MMRTG to power its octocopter. Dragonfly, targeting launch in 2026, is destined for surface and aerial exploration of Saturn's moon Titan in the 2030s.

Discovery and New Frontiers AOs may continue to allow Principal Investigators (PIs) and their mission teams to consider radioisotope power in their proposals and concepts. The recent Discovery 2019 AO allowed proposing use of up to two MMRTGs and/or use of LWRHUs. One of the proposed missions selected for a further concept study, the Trident mission, proposes a flyby of Neptune's moon Triton. Of note, this cost-capped Discovery AO mission proposal successfully accommodated the costs of two MMRTGs and associated launch costs, demonstrating that scientifically meritorious Discovery-class missions are capable of proposing RPS in their plans.

The RPS Program, with DOE and other NASA organizations as partners, has been successful at systematically reducing the cost to missions in providing fueled and tested generators, and in the costs to meet policy requirements and certify in accordance with launch authorization processes. The cost reductions are, in part, a result of shorter schedule durations for specific activities. Specifically looking at the three missions from above, progressive improvements can be seen. CRP 
principles were beginning to be applied in the Mars 2020 MMRTG preparations, demonstrating a peak of 18 FC being manufactured over a 12-month span. The Perseverance rover's generator actual preparation costs are $\$ 61 \mathrm{M}$, a $16 \%$ decrease from the initial $\$ 73 \mathrm{M}$ estimate. (The RPS Program did not manage costs for Mars 2020 launch authorization.) For NF-4, the change in approach to CRP occurred between the draft AO (cost target of \$133M) to \$73M in the final AO, accounting for both the MMRTG and the launch authorization costs, a savings of $45 \%$ for Dragonfly. For the Discovery 2019 AO, PI-managed costs (adjusted to account for acquisition of an additional MMRTG) for fueling, testing, and launch processes were stable at $\$ 64 \mathrm{M}$, at a slight reduction from the NF-4 estimated costs, even accounting for real-year cost adjustments. This reduction anticipates the continued savings from CRP efforts and the resultant savings from NEPA and NSPM-20 process changes for Trident, should the mission concept be selected.

\section{Other proactive steps}

The RPS Program, partnering with DOE, continues to make other investments to enable more diverse mission capabilities through systems and process improvements beyond successfully reestablishing a sustained supply of $\mathrm{PuO}_{2}$ and the transition to CRP activities outlined earlier.

\section{New RPS Configurations}

The only existing flight RPS configuration available to NASA missions is the MMRTG. While the RPS Program continues to ensure availability of MMRTGs, the Program also continues to invest in advances in thermal energy conversion technologies, both in thermoelectric (static) and dynamic conversion approaches. Leveraging the updated 2016 MOU roles, the RPS Program initiated a NASA-led project in 2018 to develop a new vacuum-rated RPS by $2028 .{ }^{6}$ This new RPS targets improved performance over the heritage GPHS-RTGs (e.g. on Cassini) and the inclusion of a modular system configuration. The project established multiple contracts via a DOE acquisition. DOE and NASA are utilizing a Strategic Partnership Projects (SPP) approach, allowing NASA flight system and DOE nuclear system standards to be addressed in a single, shared project to achieve a common objective. SPPs provide other federal agencies access to DOE's unique capabilities and expertise to achieve mission goals and objectives that otherwise are not available through private entities.

\section{Policy Changes and Process Improvements}

Several actions have been taken over the past few years to simplify the process for launching RPS while maintaining safety and environmental protection. ${ }^{7}$ The simplification of meeting regulatory requirements allows a shorter cycle-time for missions to ensure compliance, reducing a historical 7-10 year timeframe downward to 3-5 years. A brief description of these actions follows.

\section{National Environmental Policy Act (NEPA) Process Improvements}

NEPA requires federal agencies to analyze potential environmental impacts during program and project decision making. NEPA compliance is conducted in a transparent manner, informing the public of agency intentions. NASA completed the development of a Programmatic Environmental Assessment (PEA) for missions that would use only LWRHUs. The PEA satisfies NASA's obligations under NEPA for missions that fit within its parameters and thus would not necessitate a mission-specific NEPA action. This is not unlike the NASA Payloads PEA, used over 50 times to date. The LWRHU PEA covers spacecraft launched from Kennedy Space Center (KSC) and Cape Canaveral Air Force Station in Florida. The use of a PEA approach in contrast to the 
historical mission-specific Environmental Impact Statement (EIS) saves both time and cost. The PEA, now completed and referenceable, removes a need for a year's long, \$1-2M per-mission EIS effort, while having still provided the public insight into NASA's intentions and potential environmental impacts. Comparable streamlining approaches, while maintaining compliance, are also underway for mission-specific RPS utilization. Similar cost and time savings are anticipated.

\section{A Change to National Space Policy}

In June 2018, existing nuclear launch authorization process and policies were reviewed. The nuclear policy fell within Presidential Directive/National Security Council-25 (PD/NSC-25). The PD/NSC-25 authorization process took a "one size fits all” approach - all launches went through the same process regardless of the amount of material or risk level. This review resulted in the issuance of a revised policy. On August 20, 2019 a new National Security Presidential Memorandum (known as NSPM-20) ${ }^{8}$ was issued, supplanting the relevant portion of PD/NSC-25.

The new policy establishes safety guidelines to assist mission planners and launch authorization authorities in ensuring launch safety across envisioned space nuclear systems including RPS and potential future fission-based systems. The policy also directs that safety analyses incorporate past experience to maximize effectiveness and efficiency. It created a standing Interagency Nuclear Safety Review Board (INSRB), replacing ad hoc mission-specific interagency panels.

Perhaps most importantly, the new policy structures launch authorization for space nuclear systems to follow a tiered process based on system characteristics, level of potential risk, and national security considerations. While launches in all tiers require safety analysis, review, and reporting, only Tiers II and III require INSRB review, and only Tier III requires Presidential authorization.

The requirements of NSPM-20 have already been applied on NASA missions. The Perseverance launch was deemed to be at a Tier II level, and was approved by the NASA Administrator, reducing procedural burdens while not compromising safety or mission success.

\section{Leveraging DOE's Safety Analysis Approach}

Finally, the DOE is developing system specific safety analyses that align with NSPM-20 and uses the Department's established nuclear safety analysis framework and risk-based processes. These Documented Safety Analyses (DSAs) establish, first for LWRHUs and later for common technology-based RPS configurations, a safety envelope for the system. When used in conditions defined by the envelope, the system DSAs can be applied on a variety of missions, reducing the need to repeat duplicative analyses for each launch while still ensuring system safety is maintained.

These policy and process changes streamline the Nuclear Launch Authorization scope placed on missions and remove these activities from the mission's critical path schedule, reducing costs as well. It is expected these improvements could save applicable missions as much as $\$ 30$ million in review, analysis and authorization costs without compromising safety. Savings such as these have been planned into the costs provided in Discovery and New Frontiers AOs as described above.

\section{Conclusion}

The United States is a recognized world leader in deep space and planetary surface exploration; this leadership is enabled by the unique capabilities provided by $\mathrm{Pu}-238$ fueled radioisotope power 
systems. Radioisotope-powered missions have resulted in discoveries that have rewritten science textbooks.

Although the NRC (2009) report painted a dire picture, the near 30-year gap in U.S. production of $\mathrm{Pu}-238$ is over. NASA and DOE planned and executed efforts reestablishing a Pu-238 capability. DOE continues to scale up production of a steady, maintainable, and adjustable supply of heat sources using existing DOE capabilities and processes. Production rates are sized to meet the needs of envisioned NASA RPS missions. And NASA and DOE went beyond simply reestablishing this production capability.

A series of actions were taken, and RPS-related risks reduced across the RPS enterprise:

- Plutonium-238 production has been reestablished and continues;

- A continuing production of flight-ready heat sources is matched to forecasted mission needs; and

- $\quad$ Policy and process changes are enabling more efficient procedural steps toward launch.

The last decade of investment by NASA, in partnership with DOE, has seen critical progress stabilizing, and in fact advancing NASA's ability to explore the solar system using radioisotope power. The use of robust and prevalent radioisotope power system capabilities can once again be considered a viable mission enhancing or enabling choice. From surviving and operating through the extended darkness of a lunar night, to exploration of destinations distant from the Sun, and through the operation of missions where atmospheres may obscure solar power, radioisotope technologies offer power to explore.

\section{$\underline{\text { References }}$}

1. Implementation of Cross-Agency Nuclear Applications; June F. Zakrajsek, et al; Nuclear and Emerging Technologies for Space (NETS), American Nuclear Society (ANS) Topical Meeting, 2019.

2. Radioisotope Power Systems: An Imperative for Maintaining U.S. Leadership in Space Exploration, National Research Council, 2009.

3. Plutonium-238 Supply Project-Additional Processing Enabling Power for Future NASA Missions; Robert M. Wham, et al, IEEE Aerospace, 2016.

4. Constant Rate Production: DOE Approach to Meeting NASA Needs for Radioisotope Power Systems for Nuclear-Enabled Launches; Robert M. Wham, et al; American Journal of Aerospace Engineering, 2018.

5. DOE Could Improve Planning and Communication Related to Plutonium-238 and Radioisotope Power Systems Production Challenges; U.S. Government Accountability Office report GAO-17-673, 2017.

6. Radioisotope Power Systems - An Interagency Program Status, Thomas J. Sutliff, et al.; NETS, ANS Society Topical Meeting, 2019.

7. Improving the Nuclear Launch Approval Process; Progress and Plans, Peter W. McCallum, NETS, ANS Topical Meeting, 2019.

8. National Security Presidential Memorandum-20, https://www.whitehouse.gov/presidential-actions/presidential-memorandum-launchspacecraft-containing-space-nuclear-systems/, August, 2019. 